\title{
Performance of a Venturi Scrubber in the Removal of Fine Powder from a Confined Gas Stream
}

Maria Angélica Martins Costa, Ana Paula Rodrigues Alves Ribeiro, Érica Rodrigues Tognetti,

Mônica Lopes Aguiar, José Antônio Silveira Gonçalves, José Renato Coury*

Departamento de Química, Universidade Federal de São Carlos, C.P. 676, 13565-905 São Carlos - SP, Brazil

Received: November 23, 2003; Revised: March 19, 2005

\begin{abstract}
Experimental results on the performance of a laboratory scale rectangular Venturi scrubber in the removal of fine mineral particles from a confined air stream are presented, and a new correlation is proposed and evaluated. The scrubber was operated with air velocities in the throat varying from $58 \mathrm{~m} / \mathrm{s}$ to $75 \mathrm{~m} / \mathrm{s}$ and liquid flow rates varying from $280 \mathrm{ml} / \mathrm{min}$ to $900 \mathrm{ml} / \mathrm{min}$. Liquid was injected as a jet emerging from a $1.0 \mathrm{~mm}$ orifice at the throat. Results for dust collection grade efficiency varied from $87 \%$ to $98 \%$ for particles from $0.1 \mu \mathrm{m}$ to $2.0 \mu \mathrm{m}$.
\end{abstract}

Keywords: venturi scrubber, collection efficiency, gas cleaning, pollution control

\section{Introduction}

Venturi scrubbers are widely used equipments for simultaneous separation of fine particulate matter and toxic gases from industrial gaseous effluents. Venturi scrubbers find application in many industries such as iron and steel foundries, metallurgic industries, cement production, ceramic industries and others. They are usually compact equipments of simple construction, and can handle well hot gases and sticky or inflammable particles. Their main disadvantage is the power required for operation ${ }^{2}$.

A typical Venturi scrubber is shown if Figure 1. It consists of a convergence, a throat, and a diffuser. The gas is accelerated in the convergence to reach a velocity between $45 \mathrm{~m} / \mathrm{s}$ to $120 \mathrm{~m} / \mathrm{s}$ in the throat. In the diffuser the gas is decele rated allowing some pressure recovery. Liquid is most often introduced as jets through orifices at the beginning of the throat. The high energy of the gas promotes the atomization of the jets into a large number of small droplets.

The collection of particulate matter occurs due to collisions between particles and droplets and it is a complex function of scrubber geometry, gas and liquid flow rates, jet penetration, dust size, droplet size distribution, droplet dispersion in the throat and fraction of liquid flowing as a film on the walls of the equipment $t^{4-6}$.

The purpose of the present study is to investigate experimentally the performance of a laboratory scale Venturi scrubber in the collection of fine powder, as a function of gas and liquid flow rates, and to propose a correlation for the observed data.

\section{Experimental Arrangement}

The rig used in this work is shown in Figures 2 and 3. The dimensions of the rectangular Venturi scrubber, mounted horizontally, are shown in Table 1. Liquid was injected in the throat through a single $1 \mathrm{~mm}$ orifice. A cyclone for liquid-gas separation, a blower and a dust generation system were also part of the rig.

The dust used was a mineral rock, insoluble in water, with density of $3030 \mathrm{~kg} / \mathrm{m}^{3}$ and mass mean diameter of $5.8 \mu \mathrm{m}$. The aerosol sampling system consisted of a probe, a Millipore filter, a vacuum pump and a flow meter. The sampling was isokinetic. The two sampling points were located before the scrubber and after the cyclone, as shown in Figure 2. The sampled dust was weighted and analyzed for size distribution with a Malvern Mastersize equipment, which uses laser diffraction for particle sizing. The global and grade efficiencies were determined by Equations 1 and 2 respectively.

$$
\begin{aligned}
& \eta_{G}=1-\frac{\dot{m}_{\text {out }}}{\dot{m}_{\text {in }}} \\
& \eta\left(d_{P}\right)=1-\frac{\dot{m}_{\text {out }} f_{\text {out }}\left(d_{P}\right)}{\dot{m}_{\text {in }} f_{\text {in }}\left(d_{P}\right)}
\end{aligned}
$$

where $\dot{m}$ is the total dust mass flow rate, $f\left(d_{p}\right)$ is the fraction of particles of size $d_{p}$ in the dust and the subscripts in and out refer to conditions at the inlet and outlet of the Venturi, respectively.

The variables studied were the throat gas velocity $(58.3,66.6$ and $74.9 \mathrm{~m} / \mathrm{s})$, liquid flow rate $(286,586$ and $886 \mathrm{ml} / \mathrm{min})$ and throat length $(63,90$ and $117 \mathrm{~mm})$.

\section{Results and Discussion}

Grade efficiencies results are shown in Figures 4 to 7 . It can be observed the existence of a minimum in the grade efficiency curves, which occurs for particles of approximately $0.3 \mu \mathrm{m}$. Particles either greater or smaller than that are collected more efficiently. This behavior is probably due to the presence of two collection mechanisms: inertial impaction, responsible for the collection of larger particles, and a diffusion mechanism acting primarily on the smaller particles.

The effect of the liquid flow rate can be seen in Figure 4. In general, increasing the amount of liquid increases the efficiency. However, a combination of high liquid usage with small orifices can lead to excessive jet penetration. In this situation, the jet will atomize near the opposite wall facilitating droplet deposition and thus decreasing the amount of liquid available as droplets.

The effect of the throat gas velocity is illustrated in Figure 5. An increase in gas velocity is normally accompanied by an increase in collection efficiency. However, this increase is not linear, and beyond a certain gas velocity the gain in efficiency is small and not justified in view of the higher pressure drop and higher energy required for the operation.

A new correlation (Equation 3) has been proposed to take into account the trends discussed above.

$\eta\left(d_{P}\right)=1-\exp \left[-51.9\left(\frac{Q_{l}\left(1-F_{f}\right) \rho_{l} D_{d}}{A_{t h} \mu_{g}}\right)^{0.19}\left(\psi^{0.169}+2813 \mathrm{Pe}^{-0.581}\right)\right](3)$ where $Q_{l}$ and $\rho_{l}$ are the liquid flow rate and density, $D_{d}$ is the droplet diameter, calculated according to Boll et al. ${ }^{1}, F_{f}$ is the fraction of 


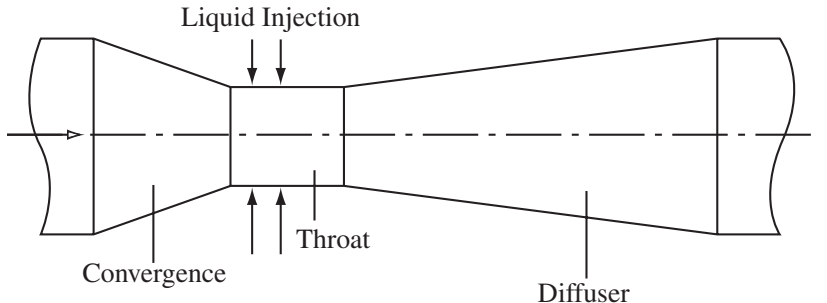

Figure 1. Schematic representation of a Venturi scrubber.

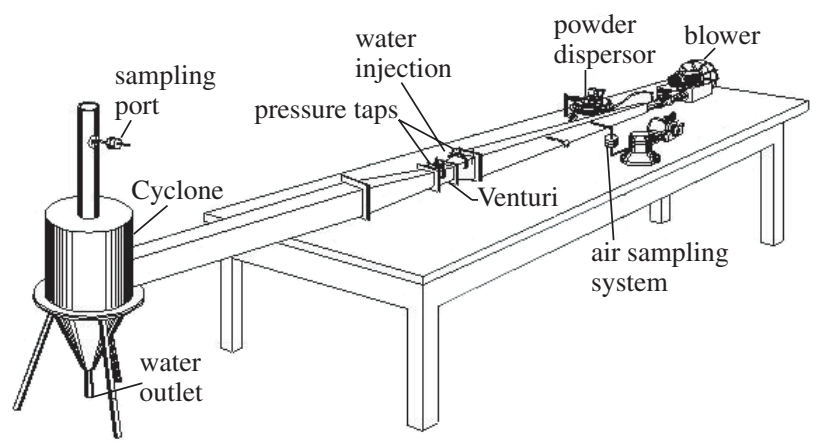

Figure 2. The rig used in this work.

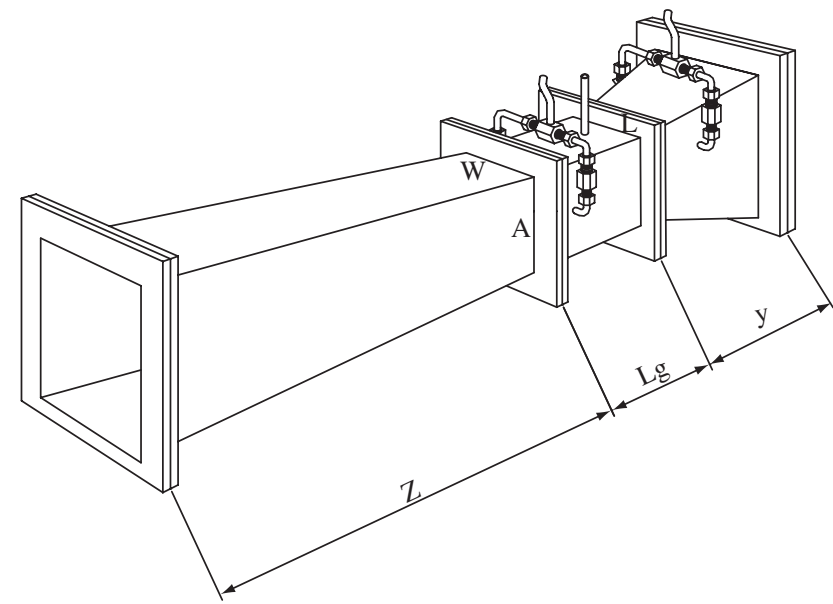

Figure 3. The rectangular Venturi Scrubber was constructed in modules, allowing the study of different throat lengths. The pressure taps and the liquid injection orifice are also shown in the drawing. Refer to Table 1 for the Venturi measurements.

Table 1. Venturi scrubber dimensions.

\begin{tabular}{lcr}
\hline \multicolumn{1}{c}{ Dimension } & Symbol & Length $(\mathrm{mm})$ \\
\hline Convergence length & $\mathrm{y}$ & 280 \\
Diffuser length & $\mathrm{Z}$ & 63,90 or 117 \\
Throat length & $\mathrm{Lg}$ & 99 \\
Throat width & $\mathrm{W}$ & 23 \\
Throat height & $\mathrm{A}$ & 35 \\
\hline
\end{tabular}

liquid flowing as film, calculated according to Gonçalves et al. ${ }^{3}, A_{\text {th }}$ is the throat cross sectional area, $\mu_{g}$ is the gas viscosity, $\psi$ is the inertial impaction parameter and $\mathrm{Pe}$ is the Peclet number. This correlation assumes that there are two collection mechanisms operating, the inertial mechanism, represented by the parameter $\psi$ and the diffusion mechanism, represented by the Pe number, given respectively by

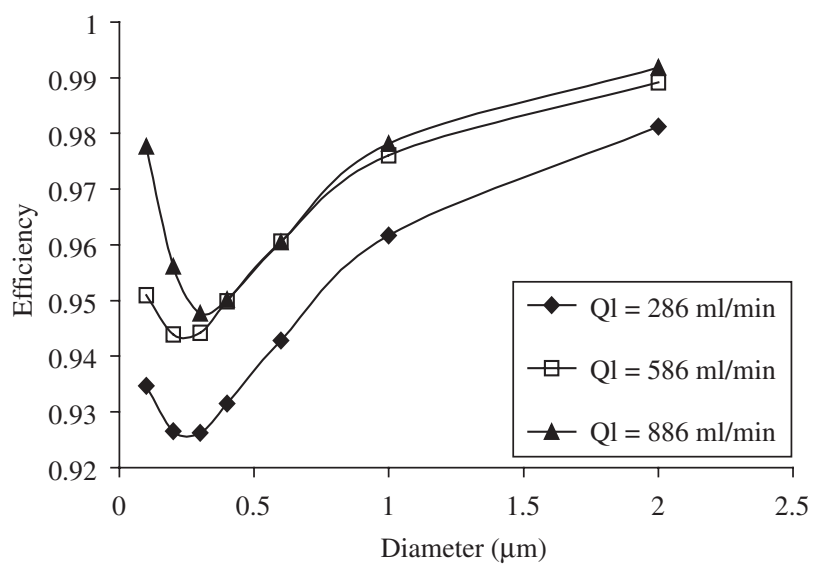

Figure 4. Effect of the liquid flow rate in the collection grade efficiency. $V_{g}=6.6 \mathrm{~m} / \mathrm{s}$ and $L_{g}=90 \mathrm{~mm}$.

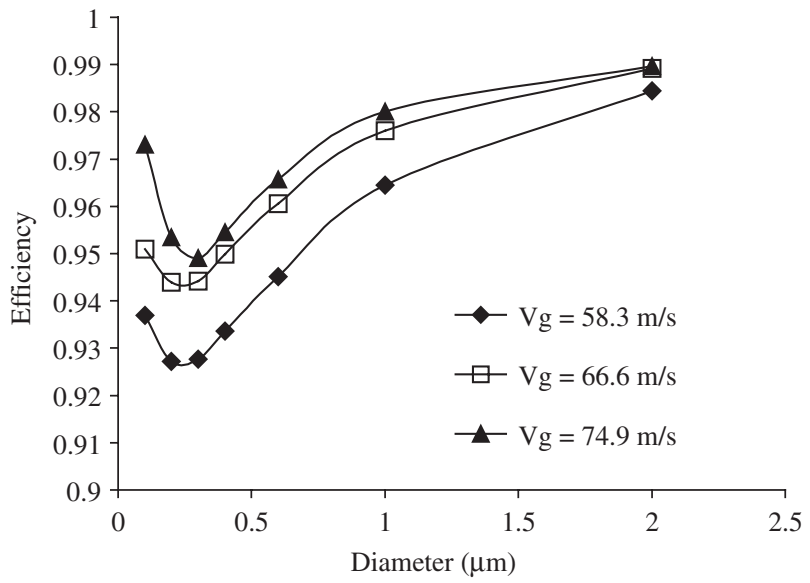

Figure 5. Effect of the throat gas velocity on collection grade efficiency. $Q_{l}=586 \mathrm{ml} / \mathrm{min}$ and $L_{g}=63 \mathrm{~mm}$.

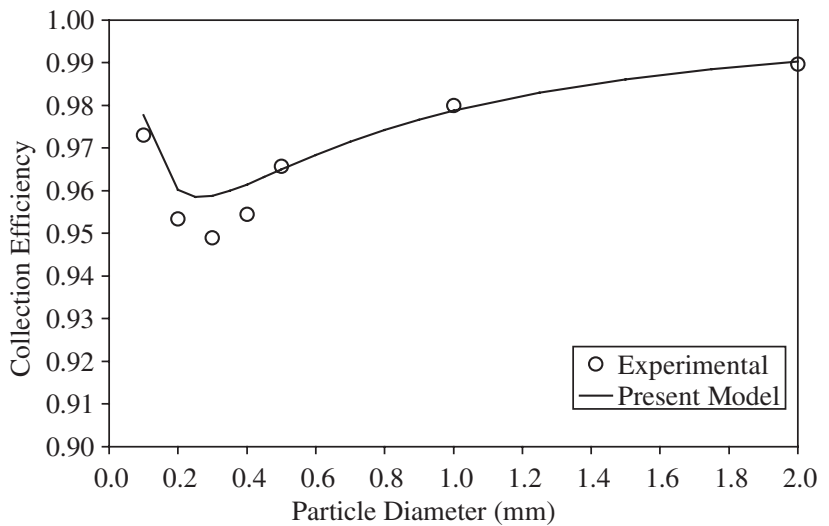

Figure 6. Comparison between experimental and predicted collection grade efficiency. $V_{g}=74.9 \mathrm{~m} / \mathrm{s}, Q_{l}=586 \mathrm{ml} / \mathrm{s}, L_{g}=90 \mathrm{~mm}$.

$$
\begin{gathered}
\psi=\frac{\rho_{P} d_{P}^{2} V_{g} C}{18 \mu_{g} D_{d}} \\
\mathrm{Pe}=\frac{V_{g} D_{d} 3 \pi \mu_{g} d_{P}}{K_{B} T C}
\end{gathered}
$$




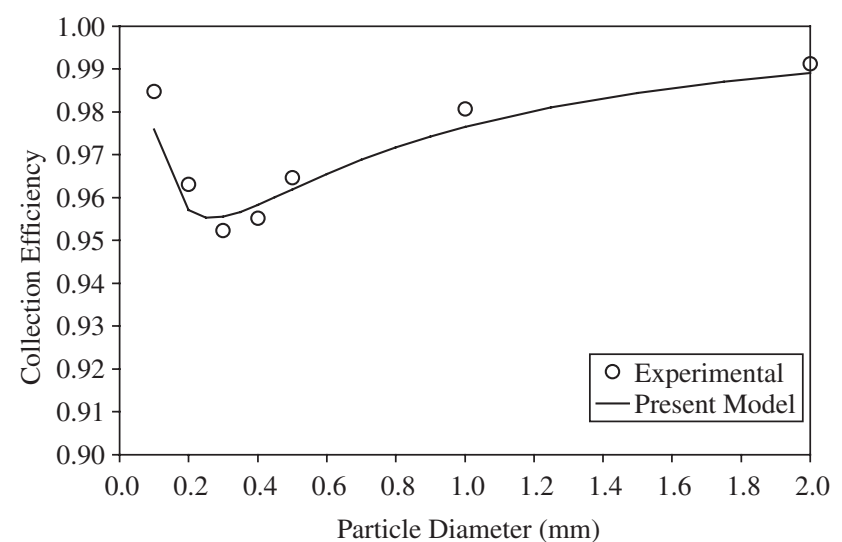

Figure 7. Comparison between experimental and predicted collection grade efficiency. $V_{g}=66.6 \mathrm{~m} / \mathrm{s}, Q_{l}=586 \mathrm{ml} / \mathrm{s}, L_{g}=63 \mathrm{~mm}$.

where $d_{p}$ is the particle diameter, $K_{B}$ is the Boltzmann Constant $\left(1,38 \times 10^{-23} \mathrm{~J} / \mathrm{K}\right), \mathrm{T}$ is the temperature $(\mathrm{K})$, and $\mathrm{C}$ is the Cunninghan coefficient.

Figure 8, which includes all the data from the present experiments, shows that the values predicted by the new correlation are within $5 \%$ of the experimental data.

\section{Conclusions}

From the above, it may be concluded that:

- Collection efficiency increases with liquid usage up to a certain point, when excessive jet penetration may be responsible for a rapid increase in film fraction, thus actually diminishing the effective amount of liquid available as droplets;

- Collection efficiency increases with throat gas velocity;

- Grade efficiency curves exhibit a minimum for particles of about $0.3 \mu \mathrm{m}$, indicating that two collection mechanisms may be operating, one predominant for greater particles, and another for smaller particles; and

- The new proposed correlation predicted the experimental values within $5 \%$.

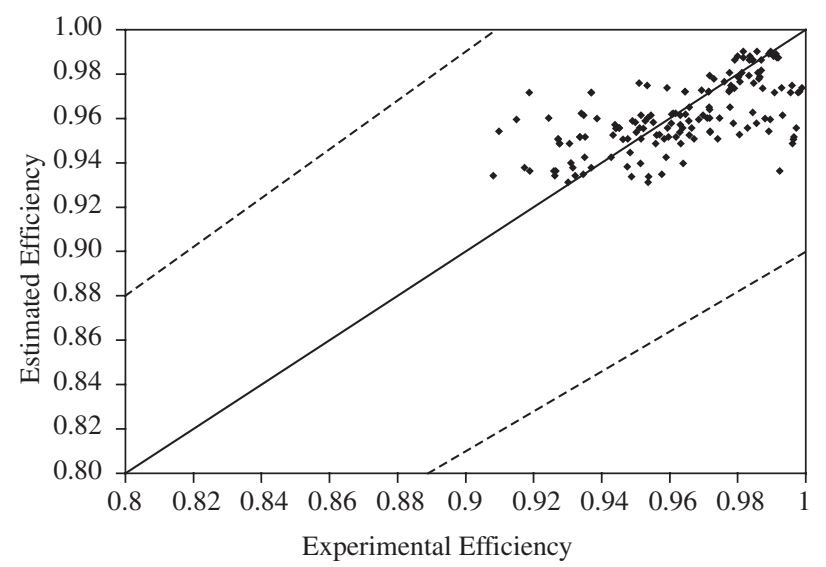

Figure 8. Comparison between predicted and experimental collection grade efficiencies.

\section{Acknowledgments}

The authors are grateful to PRONEX, FINEP, FAPESP and CNPq for the support given.

\section{References}

1. Boll RH, Flais LR, Maurer PW, Thompson WL. Mean drop size in a full scale Venturi scrubber via transmissometer. Journal of the Air Pollution Control Association. 1974; 24:934-938.

2. Calvert S. How to choose a particulate scrubber. Chemical Engineering. 1977; 19:54-68.

3. Gonçalves JAS, Martins Costa MA, Fernández Alonso D, Coury JR. Estimativa da fração de filme em lavadores Venturi. In: Maciel,R, editor. Anais do XIII Congresso Brasileiro de Engenharia Química; 2000 September 24-27; Águas de São Pedro, Brazil. [CD-ROM].

4. Oliveira CA, Coury JR. Performance of a Venturi scrubber in the removal of inhalable particles from the air. Brazilian Journal of Chemical Engineering. 1996; 13(1):9-20.

5. Taheri M, Sheih CM. Mathematical modeling of atomizing scrubbers. AIChE Journal. 1975; 21:153-157.

6. Viswanathan S. Modeling of Venturi scrubber performance. Industrial and Engineering Chemistry Research. 1977; 36(10):4308-4317. 